Research Article

\title{
Exact Dynamic Characteristic Analysis of Steel-Concrete Composite Continuous Beams
}

\author{
Qikai Sun $\mathbb{D}^{1},{ }^{1}$ Nan Zhang $\left(\mathbb{D}\right.$, Guobing Yan, ${ }^{2}$ Xinqun Zhu, ${ }^{3}$ Xiao Liu, and Wangwang Li \\ ${ }^{1}$ School of Civil Engineering, Beijing Jiaotong University, Beijing 100044, China \\ ${ }^{2}$ Railway Engineering Research Institute, China Academy of Railway Sciences Corporation Limited, Beijing 100081, China \\ ${ }^{3}$ School of Civil and Environmental Engineering, University of Technology Sydney (UTS), Sydney NSW 2007, Australia
}

Correspondence should be addressed to Nan Zhang; nzhang@bjtu.edu.cn

Received 28 February 2021; Revised 12 May 2021; Accepted 22 May 2021; Published 1 June 2021

Academic Editor: Pedro Museros

Copyright (C) 2021 Qikai Sun et al. This is an open access article distributed under the Creative Commons Attribution License, which permits unrestricted use, distribution, and reproduction in any medium, provided the original work is properly cited.

The free vibration characteristics of steel-concrete composite continuous beams (SCCCBs) are analyzed based on the Euler-Bernoulli beam theory. A modified dynamic direct stiffness method has been developed, which can be used to analyze the SCCCBs with some lumped masses and elastic boundary conditions. The results obtained by the proposed method are exact due to the elimination of approximated displacement and force fields in derivation. The proposed method is verified by comparing its results with those obtained by ANSYS software and laboratory tests. Then, the influencing factors on the reduction of natural frequency are analyzed and discussed in detail using the proposed method. The results show that stronger interfacial interaction results in higher values of natural frequency as well as larger steel subbeam and thinner concrete slab. The smaller the natural frequency of the SCCCBs is, the more significant effect the interfacial interaction on the natural frequency is. The reduction of natural frequency is not affected by the different numbers of spans but the equal single-span length and various ratios of the side span to the main span but equal total length, but it is influenced by the extra single-span length and different ratios of the side span to the main span but equal main span length. And it is only affected by bending stiffness. Furthermore, the reasonable ratio of the side span to the main span is $0.9 \sim 1.0$.

\section{Introduction}

Due to the clear advantages of larger spans, higher loadbearing capacities, and more convenient construction, steelconcrete composite beams (SCCBs), especially the steelconcrete composite continuous beams (SCCCBs), are widely applied in railway bridges with the development of the highspeed railway. The SCCCBs are compared with a concrete slab in the compressive portion and a steel subbeam in the tensile portion and connected by shear studs which can transfer the shear force. Therefore, the overall mechanical performance of the SCCCBs depends not only on the material properties of steel subbeam and concrete slab but also, to a large extent, on the connection performance of shear studs. The interfacial shear slip will occur between the subcomponents owing to the flexibility of shear studs, which can reduce the natural frequencies of SCCCBs significantly.
On the other hand, in practice, some lumped masses are usually attached to the SCCCBs (Figure 1), which makes the dynamic behaviors of SCCCBs more complex. Therefore, it is important to put forward a new method to analyze the dynamic performance of SCCCBs with some lumped masses.

Research studies on the dynamic characteristics of SCCBs had been well conducted. Girhammar and Pan [1] derived the governing differential equations of motion and presented the exact and approximate solutions of SCCBs with four common boundary conditions, namely: case 1-clamped-free, case 2-pinned-pinned, case 3-clampedpinned, and case 4-clamped-clamped. Afterward, exact dynamic and static analyses of SCCBs with consistent boundary conditions were conducted $[2,3]$. The eigenmode length coefficients of eigenmode $n\left(\mu_{n}\right)$ were given as follows: $\mu_{1}=1.675$ and $\mu_{n}=(n-1 / 2)^{-1}(n \geq 2)$ for case 1 ; 


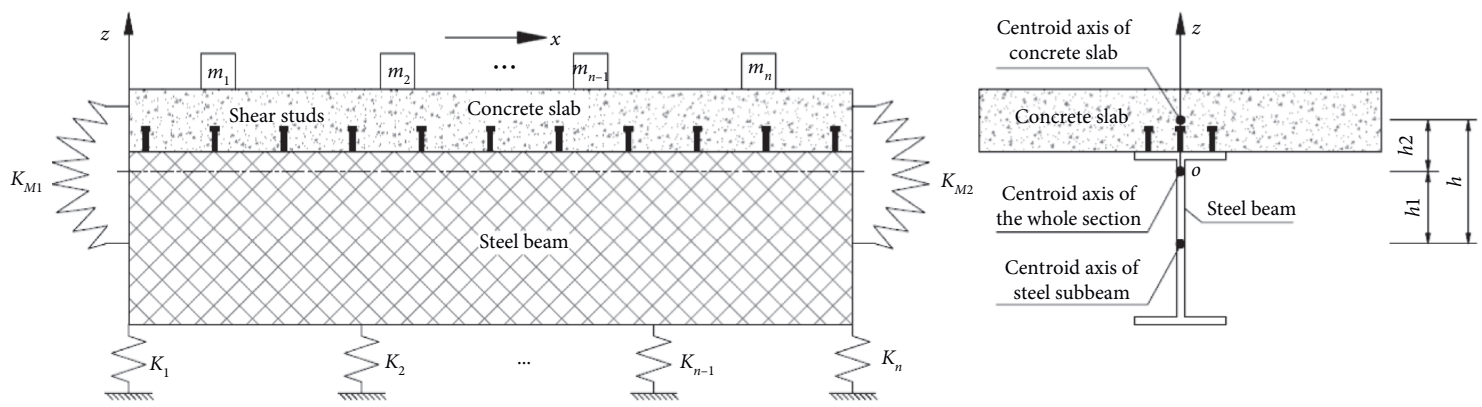

FIgURE 1: SCCCB longitudinal and cross-sectional views.

$\mu_{n}=(n \pm 0)^{-1}$ for case $2 ; \mu_{n}=(n+1 / 4)^{-1}$ for case $3 ; \mu_{n}=$ $(n+1 / 2)^{-1}$ for case 4 . These are of great significance to approximately analyze the dynamic performance of SCCBs in practice. Wu et al. [4] and Grundberg et al. [5] derived the governing differential equations of motion for the SCCBs with axial force and proposed an approximate simple expression to predict the fundamental frequency. Huang and $\mathrm{Su}$ [6] gave the nondimensional key parameters that govern the fundamental frequency which were a composite connection parameter and a section combination parameter. Hou et al. [7] proposed a curvature mode measurement method to identify the shear studs damage of SCCBs. Čas et al. [8] proposed a three-dimensional mathematical model for analyzing the dynamic behaviors of SCCBs. It indicated that the deformations in transverse XZ and lateral XY planes are mutually independent. Sun et al. [9] proposed a finite element method, which can be used to analyze the SCCBs with variable bending stiffness in the $x$-direction. The above analyses were all based on the Euler-Bernoulli beam theory.

For analyzing the influence of rotary inertia and shear deformations, some researchers [10-14] used the Timoshenko beam theory to describe the dynamic performance of each subbeam. In particular, in the analysis models of Dilena and Morassi [13] and Nguyen et al. [14], two subbeams hypothetically did not have the same rotation and curvature. For the Timoshenko beam theory, Civalek et al. [15-17] and Laura and Gutierrez [18] proposed the differential quadrature (DQ) and harmonic differential quadrature (HDQ) and discrete singular convolution method (DSC), which is of great significance to the further dynamic research of SCCBs. Some researchers [19-24] applied higher-order beam theory (Reddy beam theory [19-21] and Kant beam theory [22-24]) to analyze the dynamic characteristics of SCCBs. But the amount of computation increased because there are too many unknown parameters in those models. The above analysis about the effect of rotary inertia (RI) and shear deformations (SD) on the dynamic behaviors of SCCBs showed that SD and RI could be ignored within about 3\% error if only the first six eigenmodes were considered for simply supported SCCBs $[11,12]$. Usually, the first three eigenmodes, particularly the first eigenmode, were the most important in practice. Therefore, the study in this paper was based on the Euler-Bernoulli beam theory.

All the above research articles are about the SCCBs. Up to now, research studies on the dynamic performance of SCCCBs are insufficient. Fang et al. [25] presented a simplified calculation model and developed the Mode Stiffness Matrix to investigate the dynamic characteristics of SCCCBs. Then, using this method, the influence of span ratios and shear connection stiffness on natural frequencies was analyzed based on two-span SCCCBs. The results indicated that the natural frequency reduction ratios were totally the same for two-span SCCBs with different span ratios but uniform shear connection stiffness. However, the research targets of Fang et al. [25] were just the two-span SCCCBs and the cross-sectional stiffness ratio was a constant value, which limited the general applicability of its conclusions. Wang et al. [26] proposed a numerically stable dynamic stiffness matrix method to calculate the higherorder frequencies of SCCCBs. This method was verified by comparing the field measurements of the dynamic responses of a real multispan continuous composite bridge. In summary, research studies on the influencing factors upon the natural frequencies of SCCCBs were insufficient. Therefore, further research studies were necessary for dynamic behaviors of SCCCBs.

The dynamic stiffness matrix method mentioned in [26] was a popular and favorable finite element method, which had recently been applied to analyze the dynamic performance of SCCBs and SCCCBs [26-29]. This method was theoretically exact and useful for that with variable bending stiffness along the $x$-direction, which had been confirmed in [29]. However, on the one hand, all the above research articles did not consider the lumped masses that are attached to the beam as shown in Figure 1. On the other hand, they proposed solutions of structures under seven common boundary conditions, but its applicability to structures with elastic boundary conditions was very restricted. Among other things, there was a lack of a simple, effective calculation approach to evaluate the natural frequencies of SCCCBs.

This paper is an extension of the dynamic stiffness matrix method proposed in [29]. The purpose of this paper is to present a modified dynamic stiffness matrix method to obtain the exact natural frequencies of SCCCBs with lumped masses and elastic boundary conditions based on the Euler-Bernoulli beam theory. Utilizing the proposed modified method, a number of influencing factors upon the natural frequencies of SCCCBs, namely, interfacial interaction, cross-sectional stiffness ratio, number of spans, single-span length, the ratio of the side span to the main span, and lumped masses, are analyzed and discussed in detail. 


\section{A Modified Dynamic Direct Stiffness Method}

2.1. Basic Assumptions. All analyses in this paper are based on the Euler-Bernoulli beam theory, which ignores the shear deformation and moment of inertia. Only in-plane bending behaviors are taken into account, excluding torsion and outof-plane bending behaviors. Also, the axial motion and damping are ignored. The two subbeams can relatively slip in the $x$-direction at the interface, but they cannot separate in the $z$-direction. And the initial cohesive force at the interface between subbeams is neglected. The above assumptions are consistent with those presented earlier by Sun et al. [29].

As shown in Figure 1, the research object is the steelconcrete composite beam with variable bending stiffness along the $x$-direction caused by the uneven distribution of shear studs. The lumped masses $\left(m_{i}, m_{j}, m_{k}, m_{l} o\right)$ usually attached to the beam in practical engineering are also considered. The shear studs between the concrete slab and steel beam are regarded as continuous and uniformly distributed in the range of $L_{1}, L_{2}$, and $L_{3}$. The shear force at the steel-concrete interface per unit length $\left(Q_{L}\right)$ versus shear slip $(\delta)$ relationship is linear elastic, i.e., $Q_{L}=K_{i} \delta$, where $K_{i}$ (see Figure 1) is a constant slip modulus.
2.2. Differential Equations of Motion. If we ignore the lumped masses $\left(m_{i}\right)$ and consider the free-body microelements of SCCCBs as shown in Figure 2, the governing equation of motion can be written as follows [29]:

$$
\begin{gathered}
(E I)_{1} \theta_{, x x}=K \delta h=K h^{2}[\theta+\varphi]=K h^{2}\left[\theta+v_{, x}\right], \\
(E I)_{2} v_{, x x x x}-K_{s} h^{2}\left[\theta_{, x}+v_{, x x}\right]+\bar{m} v_{, t t}=0,
\end{gathered}
$$

where $(E I)_{1}=E_{c} A_{c} h_{2}^{2}+E_{s} A_{s} h_{1}^{2}$ is the algebraic sum of the bending stiffness of the two subbeam sections around the centroid axis of the whole cross section which can be called the slip stiffness. $E_{c}, E_{s}, A_{c}$, and $A_{s}$ are Young's modulus and the cross-sectional area of concrete slab and steel subbeam, respectively. $\theta$ and $v$ are the slip angle and the vertical displacement, respectively. $(E I)_{2}=E_{c} I_{c}+E_{s} I_{s}$ is the algebraic sum of the bending stiffness around the respective centroid axis of subbeams which can be called the bending stiffness. $\bar{m}$ is the linear meter weight that can be assumed to be a constant. $I_{c}$ and $I_{s}$ are the moment of inertia due to the bending of each subbeam. $h=h_{1}+h_{2}$ is the distance between the centroid axis of the subbeams.

Substituting equation (2) into equation (1) gives the differential equation of governing motion for the SCCCB without lumped masses as follows [29]:

$$
\left[v_{, x x x x}(x, t)+\gamma v_{, t t}(x, t)\right]-\alpha\left[\frac{1}{1+\beta} v_{, x x x x x x}(x, t)+\gamma v_{, x x t t}(x, t)\right]=0,
$$

where $\alpha=(E I)_{1} / K_{s} h^{2}, \beta=(E I)_{1} /(E I)_{2}$, and $\gamma=\bar{m} /(E I)_{\mathrm{eq}}$. $(E I)_{\mathrm{eq}}=(E I)_{1}+(E I)_{2}$ is the bending rigidity of the SCCCBs when there is no slip at the interface, i.e., $K_{s}=\infty$. It can be seen from equation (3) that there are two important parameters, namely, the composite parameter $\alpha$ in relation to the partial interaction and the nondimensional section combination parameter $\beta$ in relation to the cross-sectional stiffness ratio, which makes the motion differential equations of SCCCBs different from that corresponding to the elementary beam theory.

Based on the research of Sun et al. [29], $v(x, t)$ and $\theta(x, t)$ included in equations (1) (3) can be decoupled using the method of separating variables as the following form.

$$
\left\{\begin{array}{l}
v(x, t)=\phi(x) \sin \left(\omega_{n} t+\varsigma\right) \\
\theta(x, t)=\vartheta(x) \sin \left(\omega_{n} t+\varsigma\right)
\end{array}\right.
$$

where $\phi(x)$ and $\vartheta(x)$ are the mode functions, respectively. $\omega_{n}$ are the structural natural frequencies, and $\varsigma$ is the initial phase.

In addition, we can obtain the solution of equation (3).

$$
\begin{aligned}
\phi(x)= & A_{1} \sin \left(\lambda_{1} x\right)+A_{2} \cos \left(\lambda_{1} x\right)+A_{3} \sinh \left(\lambda_{2} x\right) \\
& +A_{4} \cosh \left(\lambda_{2} x\right)+A_{5} \sinh \left(\lambda_{3} x\right)+A_{6} \cosh \left(\lambda_{3} x\right),
\end{aligned}
$$

where the real constant $A_{i}$ can be obtained by the boundary conditions which lead to the natural frequencies and mode shapes.

2.3. A Modified 6-DOF Dynamic Stiffness Element. Figure 3 shows an SCCCB element $i$ with two lumped masses at both ends. We can see that there are six displacement boundary conditions, namely, vertical displacement $(v)$, bending angle $\left(\varphi=v_{x}\right)$, and slip angle $(\theta)$. The bending angle $\left(\varphi=v_{x}\right)$ is the same for the concrete slab and steel subbeam. The slip angle $(\theta)$ is caused by a couple of axial forces $\left(N_{c}\right.$ and $\left.N_{s}\right)$ acting on the neutral axis of the two subbeams. There are also six force boundary conditions at both ends of the element corresponding to the six displacement boundary conditions, which are shear force $(V)$, the algebraic sum of the subbeam moment $\left(M_{1}=M_{s}+M_{c}\right)$, and slip moment $\left(M_{2}=Q_{L} h\right)$. 


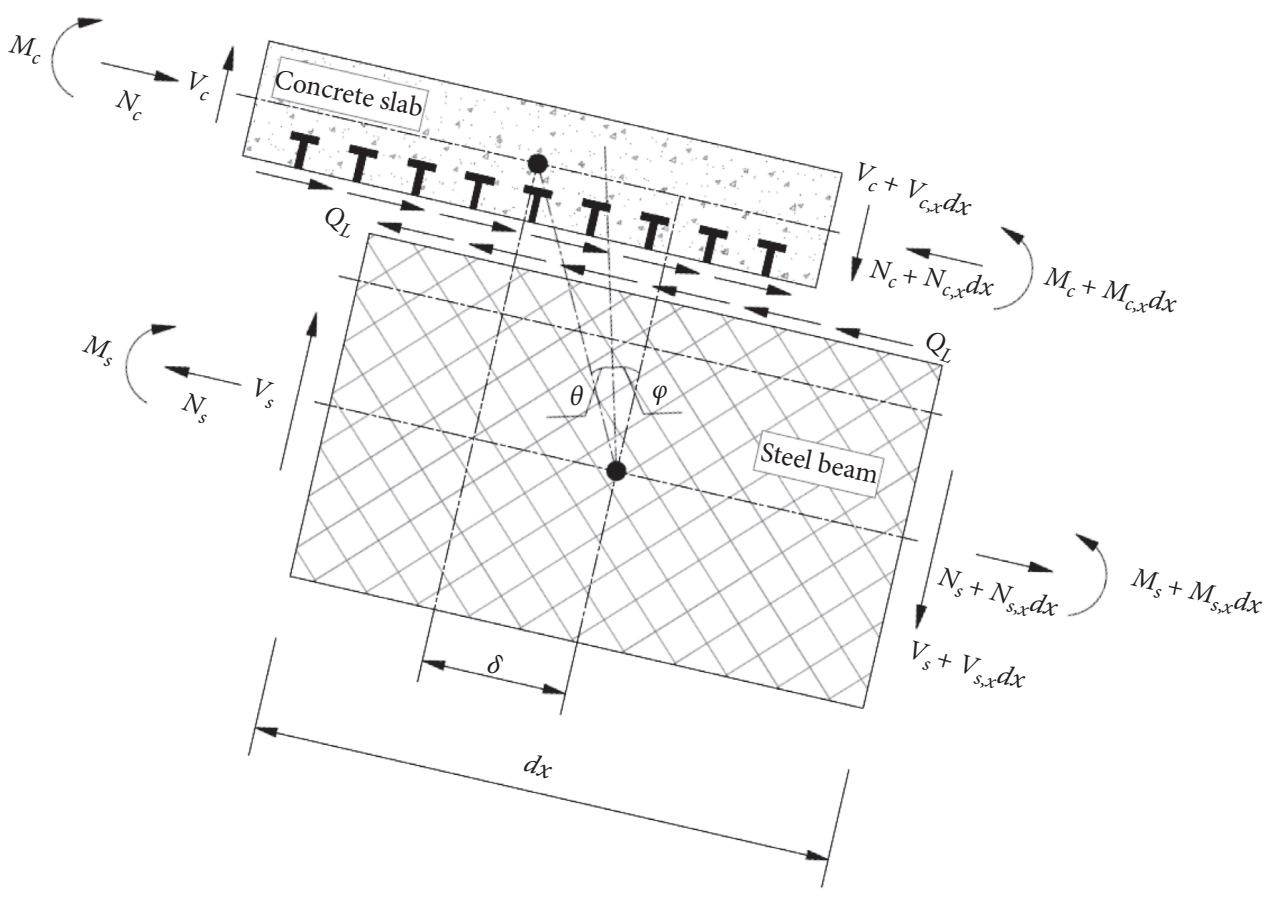

Figure 2: Analysis model of the SCCCB microelements.

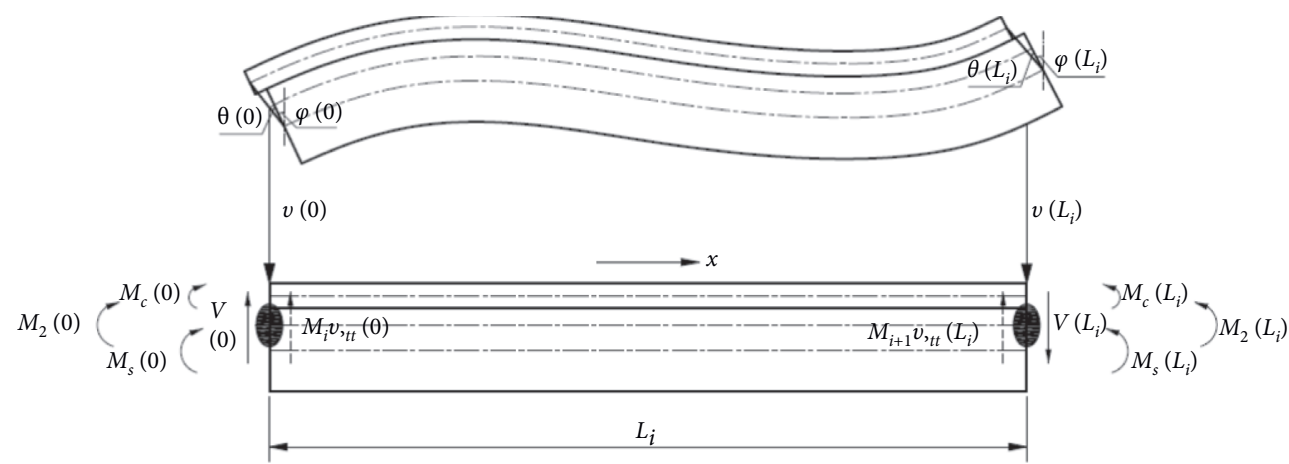

FIGURE 3: Six boundary conditions of the SCCCB element.

Considering the lumped masses $\left(m_{i}\right.$ and $\left.m_{i+1}\right)$ at both ends of the element, the six force boundary conditions can be expressed as follows, because the moment of inertia is ignored as described in the basic assumptions.

$$
\left\{\begin{array}{l}
P_{1}=V_{c}(0, t)+V_{s}(0, t)+m_{i} v_{, t t}(0, t)=(E I)_{2} \phi_{, x x x}(0)-(E I)_{1} \vartheta_{, x x}(0)-m_{i} \omega_{n}^{2} \phi(0), \\
P_{2}=M_{c}(0, t)+M_{s}(0, t)=-(E I)_{2} \phi_{, x x}(0), \\
P_{3}=-Q_{L}(0, t) h=(E I)_{1} \vartheta_{, x}(0) \\
P_{4}=V_{c}\left(L_{i}, t\right)+V_{s}\left(L_{i}, t\right)+m_{i+1} v_{, t t}\left(L_{i}, t\right)=(E I)_{1} \theta_{, x x}\left(L_{i}\right)-(E I)_{2} \phi_{, x x x}\left(L_{i}\right)-m_{i+1} \omega_{n}^{2} \phi\left(L_{i}\right), \\
P_{5}=M_{c}\left(L_{i}, t\right)+M_{s}\left(L_{i}, t\right)=(E I)_{2} \phi_{, x x}\left(L_{i}\right), \\
P_{6}=Q_{L}\left(L_{i}, t\right) h=-(E I)_{1} \vartheta_{, x}\left(L_{i}\right) .
\end{array}\right.
$$


Combining equations (1) and (2) yields the relationship between the mode shape function of slip angle $(\vartheta)$ and that of vertical displacement $(\phi)$ :

$$
\left\{\begin{array}{l}
\vartheta(x)=\frac{\alpha^{2}}{\beta} \phi_{, x x x x x}(x)-\alpha \phi_{, x x x}(x)-\left[\frac{\gamma \alpha^{2}(1+\beta)}{\beta} \omega_{n}^{2}+1\right] \phi_{, x}(x), \\
\vartheta_{, x}(x)=\frac{\alpha}{\beta} \phi_{, x x x x}(x)-\phi_{, x x}(x)-\frac{\gamma \alpha(1+\beta)}{\beta} \omega_{n}^{2} \phi(x) .
\end{array}\right.
$$

Hence, the displacement boundary conditions, namely, vertical displacement $(v)$, bending angle $\left(\varphi=v_{, x}\right)$, and slip angle $(\theta)$, can be expressed in the following form by using equations (5) and (7).

$$
\mathbf{u}=\left(\begin{array}{l}
u_{1} \\
u_{2} \\
u_{3} \\
u_{4} \\
u_{5} \\
u_{6}
\end{array}\right)=\mathbf{N}_{\mathbf{e}} \mathbf{a}=\left(\begin{array}{llllll}
N_{11} & N_{12} & N_{13} & N_{14} & N_{15} & N_{16} \\
N_{21} & N_{22} & N_{23} & N_{24} & N_{25} & N_{26} \\
N_{31} & N_{32} & N_{33} & N_{34} & N_{35} & N_{36} \\
N_{41} & N_{42} & N_{43} & N_{44} & N_{45} & N_{46} \\
N_{51} & N_{52} & N_{53} & N_{54} & N_{55} & N_{56} \\
N_{61} & N_{62} & N_{63} & N_{64} & N_{65} & N_{66}
\end{array}\right)\left(\begin{array}{c}
A_{1} \\
A_{2} \\
A_{3} \\
A_{4} \\
A_{5} \\
A_{6}
\end{array}\right),
$$

where $\quad N_{11}=N_{13}=N_{15}=0, \quad N_{12}=N_{14}=N_{16}=1$, $N_{21}=\lambda_{1}, \quad N_{23}=\lambda_{2}, \quad N_{25}=\lambda_{3}, \quad N_{22}=N_{24}=N_{26}=0$, $N_{31}=B_{1}, \quad N_{33}=B_{2}, \quad N_{35}=B_{3}, \quad N_{32}=N_{34}=N_{36}=0$, $N_{41}=\sin \left(\lambda_{1} L_{i}\right), \quad N_{42}=\cos \left(\lambda_{1} L_{i}\right), \quad N_{43}=\sinh \left(\lambda_{2} L_{i}\right)$, $N_{44}=\cosh \left(\lambda_{2} L_{i}\right), \quad N_{45}=\sinh \left(\lambda_{3} L_{i}\right), \quad N_{46}=\cosh \left(\lambda_{3} L_{i}\right)$, $N_{51}=\lambda_{1} \cos \left(\lambda_{1} L_{i}\right), \quad N_{52}=-\lambda_{1} \sin \left(\lambda_{1} L_{i}\right), \quad N_{53}=\lambda_{2} \cosh$ $\left(\lambda_{2} L_{i}\right), \quad N_{54}=\lambda_{2} \sinh \left(\lambda_{2} L_{i}\right), \quad N_{55}=\lambda_{3} \cosh \left(\lambda_{3} L_{i}\right), \quad N_{56}$ $=\lambda_{3} \sinh \left(\lambda_{3} L_{i}\right), \quad N_{61}=B_{1} \cos \left(\lambda_{1} L_{i}\right), \quad N_{62}=-B_{1} \sin \left(\lambda_{1} L_{i}\right)$,
$N_{63}=B_{2} \cosh \left(\lambda_{2} L_{i}\right), \quad N_{64}=B_{2} \sinh \left(\lambda_{2} L_{i}\right), \quad N_{65}=B$ ${ }_{3} \cosh \left(\lambda_{3} L_{i}\right)$, and $N 66=B_{3} \sinh \left(\lambda_{3} L_{i}\right) . B_{i}(i=1 \sim 3)$ can be found in Appendix.

Similarly, the six force boundary conditions at both ends, namely, shear force $(V)$, the algebraic sum of the subbeam moment $\left(M_{1}=M_{s}+M_{c}\right)$, and slip moment $\left(M_{2}=Q_{L} h\right)$, can be expressed as

$$
\mathbf{P}_{\mathbf{e}}=\left(\begin{array}{c}
P_{1} \\
P_{2} \\
P_{3} \\
P_{4} \\
P_{5} \\
P_{6}
\end{array}\right)=\mathbf{M}_{\mathbf{e}} \mathbf{a}=\left(\begin{array}{cccccc}
M_{11} & M_{12} & M_{13} & M_{14} & M_{15} & M_{16} \\
M_{21} & M_{22} & M_{23} & M_{24} & M_{25} & M_{26} \\
M_{31} & M_{32} & M_{33} & M_{34} & M_{35} & M_{36} \\
M_{41} & M_{42} & M_{43} & M_{44} & M_{45} & M_{46} \\
M_{51} & M_{52} & M_{53} & M_{54} & M_{55} & M_{56} \\
M_{61} & M_{62} & M_{63} & M_{64} & M_{65} & M_{66}
\end{array}\right)\left(\begin{array}{c}
A_{1} \\
A_{2} \\
A_{3} \\
A_{4} \\
A_{5} \\
A_{6}
\end{array}\right),
$$

where $\quad M_{11}=-(E I)_{2} \lambda_{1}^{3}-(E I)_{1} C_{1} \lambda_{1}, \quad M_{12}=M_{14}=M_{16}$ $=-m_{i} \omega_{n}^{2}, \quad M_{13}=(E I)_{2} \lambda_{2}^{3}-(E I)_{1} C_{2} \lambda_{2}, \quad M_{15}=(E I)_{2} \lambda_{3}^{3}$ $-(E I)_{1} C_{3} \quad \lambda_{3}, \quad M_{21}=M_{23}=M_{25}=0, \quad M_{22}=(E I)_{2} \lambda_{1}^{2}$, $M_{24}=-(E I)_{2} \lambda_{2}^{2}, M_{26}=-(E I)_{2} \lambda_{3}^{2}, M_{31}=M_{33}=M_{35}=0$, $M_{32}=-(E I)_{1} C_{1}, \quad M_{34}=-(E I)_{1} C_{2}, \quad M_{36}=-(E I)_{1} C_{3}$, $M_{41}=D_{1} \cos \left(\lambda_{1} L_{i}\right)-m_{i+1} \omega_{n}^{2} \sin \left(\lambda_{1} L_{i}\right), M_{42}=-D_{1} \sin \left(\lambda_{1}\right.$ $\left.L_{i}\right)-m_{i+1} \omega_{n}^{2} \cos \left(\lambda_{1} L_{i}\right), \quad M_{43}=D_{2} \cosh \left(\lambda_{2} L_{i}\right)-m_{i+1} \omega_{n}^{2} \sinh$ $\left(\lambda_{2} L_{i}\right), \quad M_{44}=D_{2} \sinh \left(\lambda_{2} L_{i}\right)-m_{i+1} \omega_{n}^{2} \cosh \left(\lambda_{2} L_{i}\right), \quad M_{45}$ $=D_{3} \cosh \left(\lambda_{3} L_{i}\right)-m_{i+1} \omega_{n}^{2} \sinh \left(\lambda_{3} L_{i}\right), M_{46}=D_{3} \sinh \left(\lambda_{3} L_{i}\right)$ $-m_{i+1} \omega_{n}^{2} \cosh \left(\lambda_{3} L_{i}\right), M_{51}=-(E I)_{2} \lambda_{1}^{2} \sin \left(\lambda_{1} L_{i}\right), M_{52}=-($
$E I)_{2} \lambda_{1}^{2} \cos \left(\lambda_{1} L_{i}\right), M_{53}=(E I)_{2} \lambda_{2}^{2} \sinh \left(\lambda_{2} L_{i}\right), M_{54}=(E I)_{2} \lambda_{2}^{2}$ $\cosh \left(\lambda_{2} L_{i}\right), M_{55}=(E I)_{2} \lambda_{3}^{2} \sinh \left(\lambda_{3} L_{i}\right), M_{56}=(E I)_{2} \lambda_{3}^{2} \cosh$ $\left(\lambda_{3} L_{i}\right), M_{61}=(E I)_{1} C_{1} \sin \left(\lambda_{1} L_{i}\right), M_{62}=(E I)_{1} C_{1} \cos \left(\lambda_{1}\right.$ $\left.L_{i}\right), M_{63}=(E I)_{1} C_{2} \sinh \left(\lambda_{2} L_{i}\right), M_{64}=(E I)_{1} C_{2} \cosh \left(\lambda_{2} L_{i}\right)$, $M_{65}=(E I)_{1} C_{3} \sinh \left(\lambda_{3} L_{i}\right)$, and $M_{66}=(E I)_{1} C_{3} \cosh \left(\lambda_{3} L_{i}\right)$. $C_{i}$ and $D_{i}(i=1 \sim 3)$ can be found in Appendix.

Combining equations (8) and (9) yields the element dynamic stiffness matrix, i.e., $\mathbf{K}_{\mathbf{e}}$, as follows:

$$
\mathbf{P}_{\mathrm{e}}=\mathbf{M}_{\mathrm{e}} \mathbf{N}_{\mathrm{e}}^{-1} \mathbf{u}_{\mathrm{e}}=\mathbf{K}_{\mathrm{e}} \mathbf{u}_{\mathrm{e}} \text {. }
$$


When analyzing the natural frequency of the SCCCBs, the overall dynamic stiffness matrix, i.e., $\mathbf{K}_{g}$, can be assumed in a similar process as the static direct stiffness method.

$$
\mathrm{P}_{g}=\mathrm{K}_{g} \mathrm{u}_{g} \text {. }
$$

The elastic boundary conditions as shown in Figure 1 can be written as follows:

$$
\left\{\begin{array}{l}
V\left(x_{i}\right)=K_{i} v\left(x_{i}\right), \\
M_{1}(x)=K_{M i} v_{, x}(x), \quad x=0, L, \\
M_{2}(x)=K_{M i} \theta(x), \quad x=0, L .
\end{array}\right.
$$

There are three typical boundary conditions usually considered: simply supported $(S)$, free $(F)$, and clamped $(C)$. For the single-span SCCBs, four different boundary conditions at both ends, namely, $S-S, C-F, C-S$, and $C-C$, are usually used in the project, which can be written as follows based on equation (12):

$$
\begin{cases}v(0)=M_{1}(0)=M_{2}(0)=v(L)=M_{1}(L)=M_{2}(L)=0, & \text { for } S-S \\ v(0)=v_{, x}(0)=\theta(0)=V(L)=M_{1}(L)=M_{2}(L)=0, & \text { for } C-F \\ v(0)=v_{, x}(0)=\theta(0)=v(L)=M_{1}(L)=M_{2}(L)=0, & \text { for } C-S \\ v(0)=v_{, x}(0)=\theta(0)=v(L)=v_{, x}(L)=\theta(L)=0, & \text { for } C-C\end{cases}
$$

where $x=0, L$ is the support position along the $x$-direction.

For the SCCCBs, the boundary conditions can be expressed as follows:

$$
v(0)=M_{1}(0)=M_{2}(0)=v\left(x_{i}\right)=v(L)=M_{1}(L)=M_{2}(L)=0,
$$

where $x=0, x_{i}, L$ is the support position along the $x$ direction.

The solving process of natural frequencies can be conveniently carried out as follows:

Step 1. Substituting the boundary conditions into equation (11) and removing the row and column with the displacement of zero in $\mathbf{K}_{g}$ give a new global dynamic stiffness matrix $K_{\mathrm{gN}}$.

Step 2. Assume the natural frequency $\omega_{n}$.

Step 3. Substitute $\omega_{n}$ into $\mathbf{K}_{g N}$, and make determinant $\left|\mathbf{K}_{g N}\right|$ equal zero.

Step 4. If the determinant is not equal to zero, then adjust $\omega_{n}$ and repeat steps $2 \sim 3$.

\section{Results and Discussions}

\subsection{Verification of the Proposed Method}

3.1.1. Example 1: Experimental Verification. This section focuses on the verification of the proposed method by a twospan SCCCB in the laboratory. The natural frequencies obtained by the proposed method were compared with those by ANSYS software and laboratory tests. Therefore, the proposed method was verified.

I-section is used as a test beam as shown in Figure 4. A concrete slab with $100 \mathrm{~mm}$ in height and $1200 \mathrm{~mm}$ in width is adopted. The density and elasticity are selected to be $\rho_{c}=$ $24 \mathrm{kN} / \mathrm{m}^{3}$ and $E_{c}=3.25 \times 10^{4} \mathrm{MPa}$, respectively. The density and elasticity of steel subbeam are $\rho_{s}=78.5 \mathrm{kN} / \mathrm{m}^{3}$ and
$E_{s}=2.06 \times 10^{5} \mathrm{MPa}$, respectively. The shear connector has a height of $80 \mathrm{~mm}$ and a diameter of $16 \mathrm{~mm}$. The span length is $2 \times 6.0 \mathrm{~m}$.

The fundamental frequencies of the test SCCCBs obtained by the proposed method, the ANSYS software, and the test in the laboratory are listed in Table 1. The experimental setup is shown in Figure 5(a). In the ANSYS Finite Element Analysis (FEA) model (see Figure 5(c)), the concrete slab is simulated using the SOLID65 element, the steel subbeam with the SHELL63 element, and the shear connector using the COMBIN39 element.

The shear-slip curve of the shear connector can be defined as follows:

$$
\left\{\begin{array}{l}
Q=Q_{u}\left(1-e^{-\beta s}\right)^{\alpha}, \\
Q_{u}=0.5 A_{\text {st }} \sqrt{E_{c} f_{c}} \leq 0.7 A_{\text {st }} f_{\text {stu }}
\end{array}\right.
$$

where $Q_{u}$ is the ultimate load of the shear connector, the coefficients $\alpha=0.7$ and $\beta=0.8$ were determined experimentally [30], $s$ is the slip displacement, $A_{\text {st }}$ is the cross section of the shear connector, $E_{c}$ and $f_{c}$ are Young's modulus and the compressive strength of the concrete slab, respectively, and $f_{\text {stu }}$ is the ultimate tensile strength of the shear connector.

Hence, the shear connector stiffness can be obtained using the secant of the shear-slip curve at $0.66 Q_{u}[7,29,31]$ as shown in Figure 6. $K$ is $2246.7 \mathrm{MPa}$ from 0 to $1050 \mathrm{~mm}$ and $11350 \mathrm{~mm}$ to $12400 \mathrm{~mm}, 1001.8 \mathrm{MPa}$ from $1050 \mathrm{~mm}$ to $5350 \mathrm{~mm}$ and $7050 \mathrm{~mm}$ to $11350 \mathrm{~mm}$, and $2353.0 \mathrm{MPa}$ from $5350 \mathrm{~mm}$ to $7050 \mathrm{~mm}$.

Table 1 shows that the eigenfrequencies of the test SCCCBs. The results show that for the first-order frequency, the results obtained by the proposed method agree well with those obtained by laboratory testing and ANSYS. In Table 1, the relative errors to the test result are within $2 \%$. However, for the second-order frequency, the errors of the proposed 


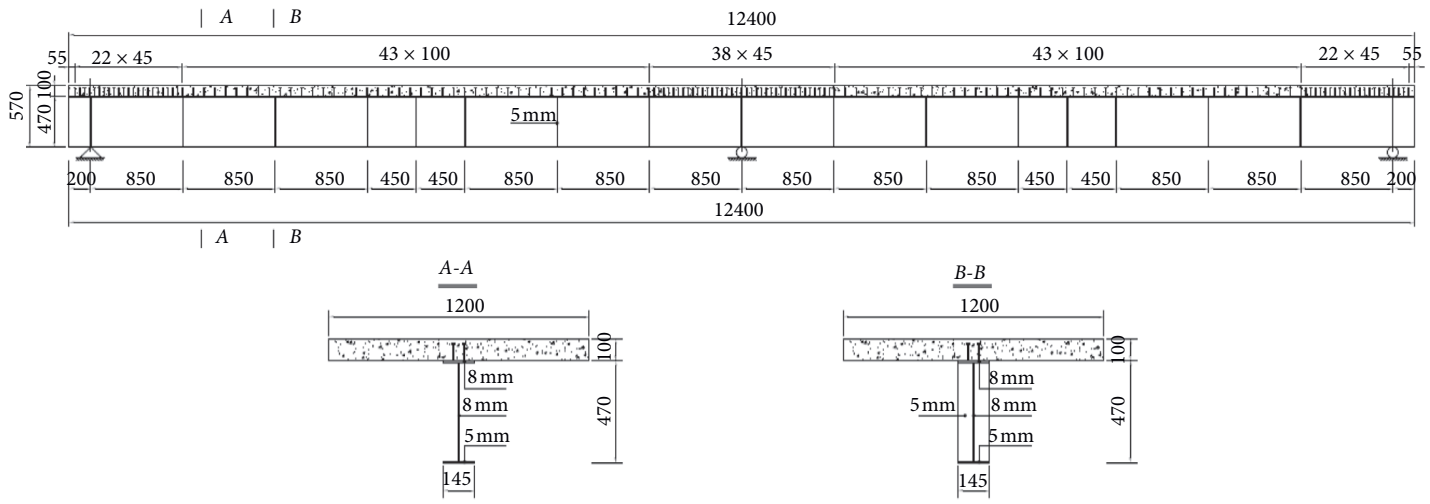

Figure 4: Beam geometry and dimensions ( $\mathrm{mm})$.

TABLE 1: A comparison between the eigenfrequencies.

\begin{tabular}{lccc}
\hline Order & Test result & ANSYS FEA & The proposed method \\
\hline 1st & 21.56 & $21.76(0.93 \%)$ & $21.32(-1.11 \%)$ \\
2nd & 25.31 & $27.06(6.9 \%)$ & $28.18(11.3 \%)$ \\
\hline
\end{tabular}

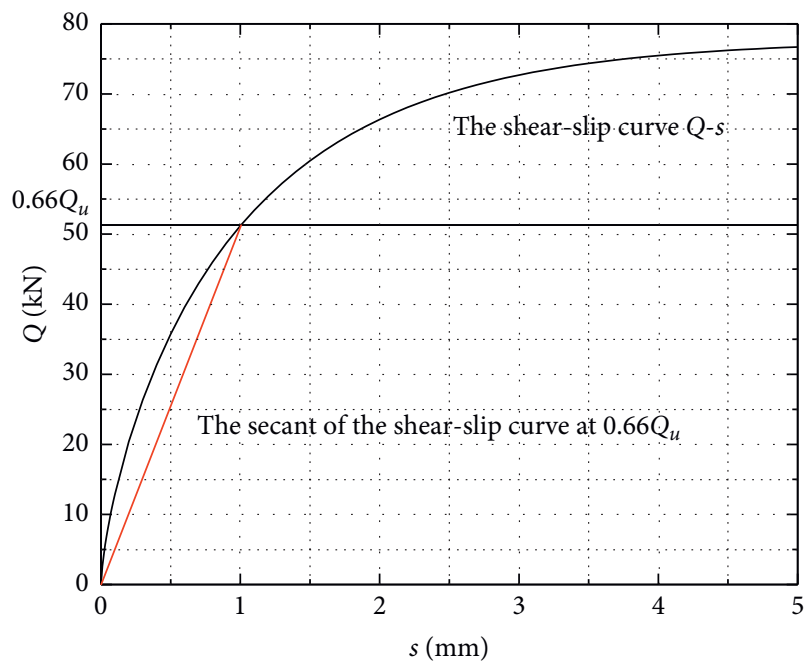

Figure 5: The beam under experimental testing and FEA modeling. (a) The test beam. (b) Test result $(21.56 \mathrm{~Hz})$. (c) FEA model. (d) FEA result.

method relative to the test results are $11.3 \%$. These errors can be attributed to the following reasons: neglecting the effect of shear deformation, longitudinal uneven arrangement of the shear connectors, division of the structural units, and measurement errors. In a word, the modified dynamic direct stiffness method can be used to analyze the dynamic characteristics of the SCCCBs with variable bending stiffness along the $x$-direction. And it is meaningful to further study the effect of shear deformations on the eigenfrequency of SCCCBs. It is worth mentioning that the research on those aspects is in the works.

3.1.2. Example 2: Numerical Example. In this section, three numerical models are applied to verify the proposed method. The cross-section dimensions and material properties of the beam are shown in Figure 7. The three models are as follows:

Case 1: a simply supported SCCB, $m_{1}=0 \mathrm{~kg}$, which are present in the published papers [6]

Case 2: a two-span SCCCB, $m_{1}=15.9 \mathrm{~kg}$ ( $5 \%$ of the weight of the beam)

Case 3: a two-span SCCCB, $m_{1}=31.8 \mathrm{~kg}(10 \%$ of the weight of the beam)

In the ANSYS FEA model (see Figure 8) of example 2, the upper and lower subbeams are all simulated using the SOLID65 element, and the shear connector using the COMBIN39 element.

Table 2 shows that the fundamental frequencies obtained by analytical solution, the proposed method in this paper, and ANSYS FEA are all about the same for simply supported SCCB with different shear connector stiffness. The maximum relative error between the proposed method and ANSYS FEA is just $1.0 \%$, which can be concluded that the results obtained by ANSYS FEA can be used as a reference to verify the proposed method.

Table 3 shows that the two results obtained by the proposed method and ANSYS FEA are basically the same, and the maximum relative error is just $0.92 \%$ for Case 2 and Case 3. The main reason is that the shear deformation and moment of inertia are ignored in the proposed method. In short, the modified dynamic direct stiffness method proposed in this paper can be used to analyze the dynamic behaviors of SCCCBs with some lumped masses.

3.2. Analysis of Influencing Factors. This section focuses on the analysis and discussion of the influencing factors: interfacial interaction, cross-sectional stiffness ratio, number of spans, single-span length, and the ratio of the side span to the main span on the natural frequencies of the SCCCBs by using the proposed method based on the numerical model as shown in Figure 7.

Equation (3) shows that two key parameters ( $\alpha$ and $\beta$ ) make the motion differential equations of SCCCBs differ from those corresponding to the elementary beam theory. Therefore, they can be used as evaluation indexes of two influencing factors: interfacial interaction and cross-sectional stiffness ratio. In engineering practice, $\alpha$ has a wide 


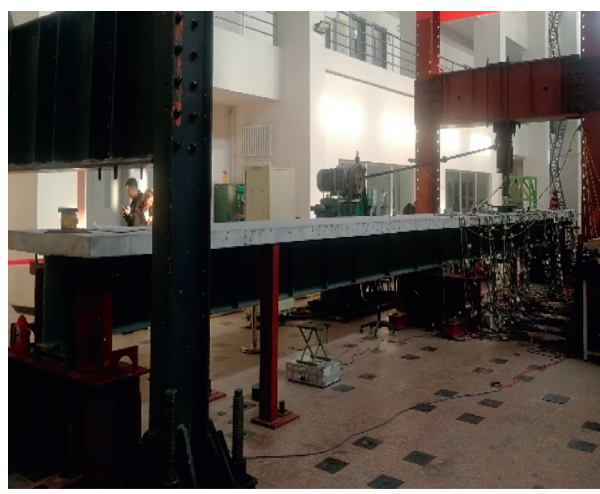

(a)

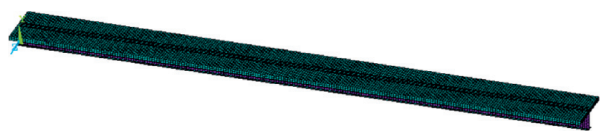

(c)

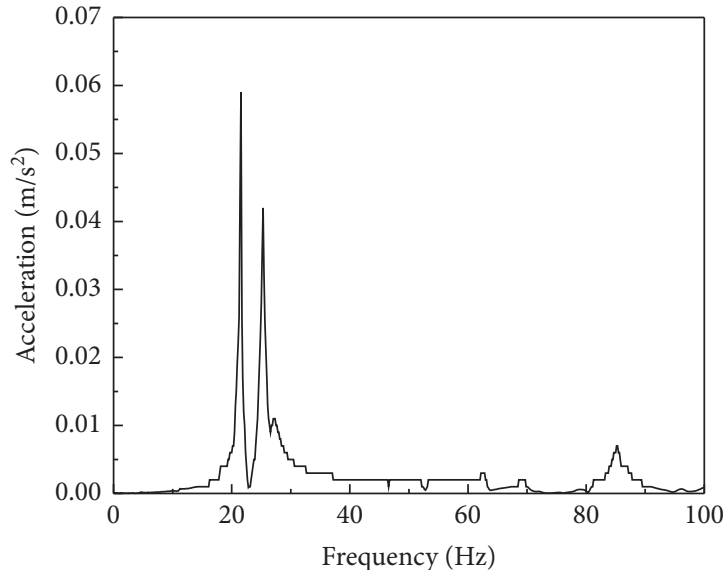

(b)

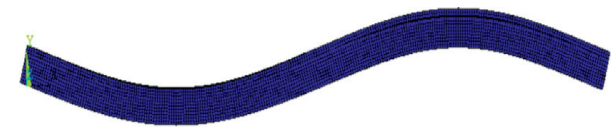

(d)

FIGURE 6: The shear-slip curve of a single stud (Q-s).
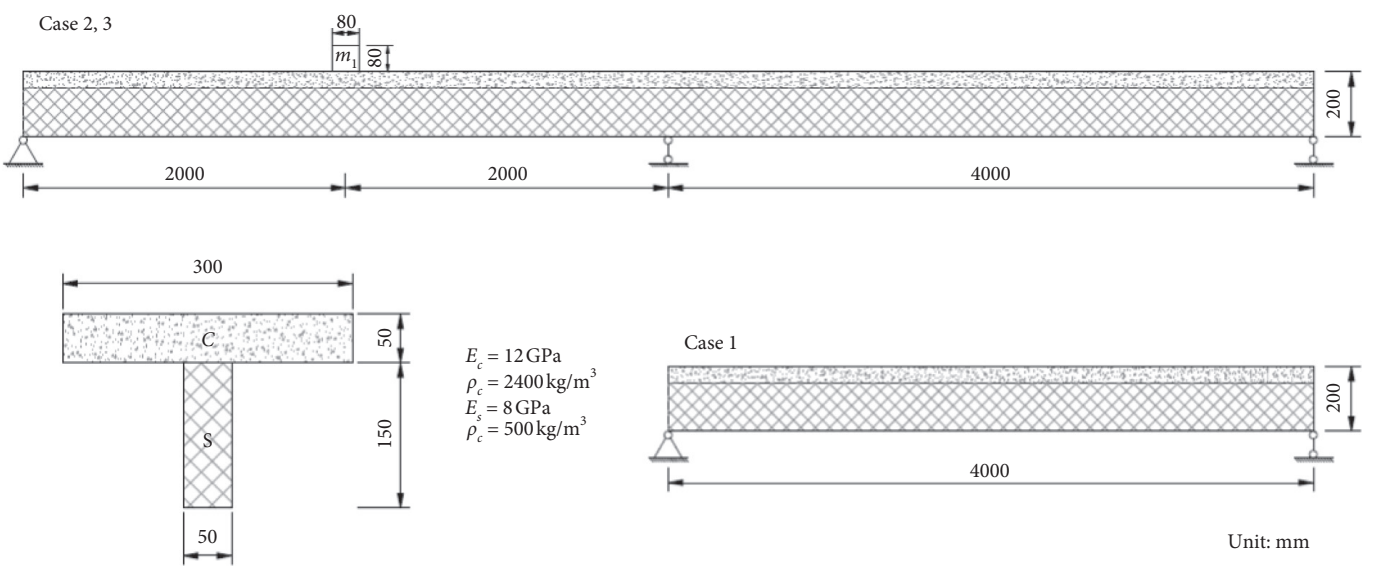

FIGURE 7: Cross-section dimensions and material properties (mm).

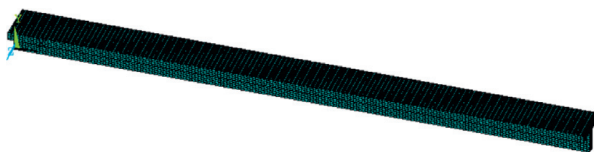

(a)

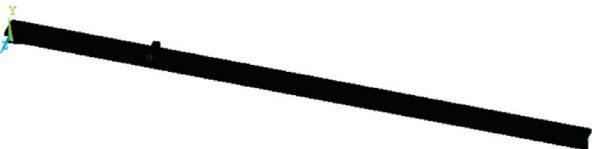

(b)

Figure 8: FEA model of example 2. (a) Case 1. (b) Case 2 and Case 3.

range of variations. When $\alpha=0\left(K_{s}=\infty\right)$, the motion differential equations can degenerate into that corresponding to the elementary beam theory. In contrast, when $\alpha=\infty \quad\left(K_{s}=0\right)$, the SCCCB degenerates into two independent subbeams. The values of $\beta$, usually, range from 0.7 to 5.0 for typical steel-concrete composite beams $[6,29]$. In addition, a higher value of $\beta$ corresponds to a thicker concrete slab and smaller steel subbeam and vice versa.

The fundamental frequency ratios $\left(\omega / \omega_{F}\right)$ calculated by equation (11) are used to evaluate the fundamental frequency reduction of SCCCB, where $\omega$ is the fundamental frequency of the steel-concrete partial interaction composite beams (PCBs, $K_{s}$ is finite) and $\omega_{F}$ is that of the steel-concrete full interaction composite beam (FCBs, $K_{s}$ is infinite).

3.2.1. Interfacial Interaction and Cross-Sectional Stiffness Ratio. The fundamental frequencies of SCCCBs with a span of $L=3 \times 4.0 \mathrm{~m}$ (three spans each with $4.0 \mathrm{~m}$ ) are attained by equation (11). Hence, the influence of interfacial interaction 
TABLE 2: A comparison of the fundamental frequencies for case 1.

\begin{tabular}{lcccc}
\hline$K(\mathrm{MPa})$ & \multicolumn{3}{c}{ Fundamental frequencies $(f / \mathrm{Hz})$} \\
& ANSYS FEA $\left(f_{\mathrm{AF}}\right)$ & Analytical solution $[3,4]\left(f_{\mathrm{AS}}\right)$ & Proposed method $\left(f_{\mathrm{PM}}\right)$ & Relative errors $\left(\left(f_{\mathrm{PM}}-f_{\mathrm{AF}}\right) / f_{\mathrm{AF}}\right) \times 100 \%$ \\
\hline Infinite & 11.94 & 12.06 & 12.06 & 1.0 \\
150 & 11.24 & 11.33 & 11.33 & 0.8 \\
100 & 10.95 & 11.04 & 11.04 & 0.8 \\
50 & 10.26 & 10.32 & 10.32 & 0.6 \\
30 & 9.60 & 9.65 & 9.65 & 0.5 \\
20 & 9.02 & 9.06 & 9.06 & 0.4 \\
10 & 8.06 & 8.08 & 8.08 & 0.2 \\
5 & 7.28 & 7.28 & 7.28 & 0.0 \\
\hline
\end{tabular}

TAвle 3: A comparison of the fundamental frequencies for Case 2 and Case 3.

\begin{tabular}{|c|c|c|c|c|c|c|}
\hline \multirow{3}{*}{$K(\mathrm{MPa})$} & \multicolumn{6}{|c|}{ Fundamental frequencies $(f / \mathrm{Hz})$} \\
\hline & \multicolumn{3}{|c|}{ Case $2\left(m_{1}=15.9 \mathrm{~kg}\right)$} & \multicolumn{3}{|c|}{ Case $3\left(m_{1}=31.8 \mathrm{~kg}\right)$} \\
\hline & $\begin{array}{l}\text { ANSYS FEA } \\
\quad\left(f_{\mathrm{AF}}\right)\end{array}$ & $\begin{array}{l}\text { Present method } \\
\left(f_{\mathrm{PM}}\right)\end{array}$ & $\begin{array}{c}\text { Relative errors } \\
\left(\left(f_{\mathrm{PM}}-f_{\mathrm{AF}}\right) / f_{\mathrm{AF}}\right) \times 100 \%\end{array}$ & $\begin{array}{l}\text { ANSYS FEA } \\
\quad\left(f_{\mathrm{AF}}\right)\end{array}$ & $\begin{array}{l}\text { Present method } \\
\qquad\left(f_{\mathrm{PM}}\right)\end{array}$ & $\begin{array}{c}\text { Relative errors } \\
\left(\left(f_{\mathrm{PM}}-f_{\mathrm{AF}}\right) / f_{\mathrm{AF}}\right) \times 100 \%\end{array}$ \\
\hline Infinite & 11.38 & 11.48 & 0.88 & 10.82 & 10.92 & 0.92 \\
\hline 150 & 10.69 & 10.77 & 0.75 & 10.15 & 10.23 & 0.79 \\
\hline 100 & 10.42 & 10.5 & 0.77 & 9.88 & 9.96 & 0.81 \\
\hline 50 & 9.75 & 9.8 & 0.51 & 9.23 & 9.28 & 0.54 \\
\hline 30 & 9.12 & 9.16 & 0.44 & 8.63 & 8.67 & 0.46 \\
\hline 20 & 8.57 & 8.6 & 0.35 & 8.11 & 8.14 & 0.37 \\
\hline 10 & 7.66 & 7.67 & 0.13 & 7.26 & 7.27 & 0.14 \\
\hline 5 & 6.92 & 6.91 & -0.14 & 6.56 & 6.55 & -0.15 \\
\hline
\end{tabular}

$(\alpha)$ and cross-sectional stiffness ratio $(\beta)$ on $\omega / \omega_{F}$ is presented in Figure 9.

Figure 9 shows that the fundamental frequencies of PCBs are all smaller than those of FCBs owing to the contribution of the flexible shear studs. However, when $\alpha=0\left(K_{s}=\infty\right)$, the value of $\omega / \omega_{F}$ equals 1 . This indicates that the partial interaction between the concrete slab and steel subbeam reduces the fundamental frequencies of SCCCBs.

For a constant value of $\beta$, the value of $\omega / \omega_{F}$ decreases steeply even when $\alpha$ changes slightly at a small level. However, it keeps a steady value at the large level. When $\beta=3.0$, the cut-off point is $\alpha=25$; it, gradually, drops with the decrease of $\beta$.

For a nonzero constant value of $\alpha$, the $\omega / \omega_{F}$ values show a nonlinear growth with the decrease of $\beta$; smaller $\beta$ values lead to a larger growth trend. This behavior indicates a weaker influence of interfacial interaction. Ultimately, the values of $\omega / \omega_{F}$ approach 1 which reveals that the dynamic behaviors of SCCCB with a thin concrete slab and large steel subbeam approach those corresponding to the elementary beam theory with the gradual decrease of $\beta$.

3.2.2. Number of Spans and Single-Span Length. Figure 10 shows the values of $\omega / \omega_{F}$ of SCCCB with different span numbers and single-span length considering that the value of $\beta$ equals 2.0. In analyzing the influence of spans' number $(\mathrm{n})$, the spans are $\mathrm{n} \times 4.0 \mathrm{~m}(n=1 \sim 5)$, whereas in that of the single-span length, $(L)$, the spans are $(3 \times L) \mathrm{m}$ $(L=4.0 \sim 8.0)$.
For the SCCCBs with different numbers of spans but equal to the single-span length, Figure 10(a) clarifies that the values of $\omega / \omega_{F}$ are basically the same as the fundamental frequencies. It is the same as the general continuous beams. $\omega / \omega_{F}$ decreases with the increase of $\alpha$ and maintains stable values when $\alpha$ is larger than 20. This refers to the fact that if the fundamental frequencies of SCCCBs are basically equal, the interfacial interaction influence is the same entirely.

For the nonzero constant value of $\alpha$, the values of $\omega / \omega_{\mathrm{F}}$ obviously increase with the increase of the single-span length as shown in Figure 10(b). Larger single-span length results in lower fundamental frequencies of SCCCBs. It indicates that smaller natural frequency leads to more influence of interfacial interaction.

3.2.3. Ratio of the Side Span to the Main Span. The values of $\omega / \omega_{F}$ of SCCCBs with different ratios of the side span to the main span, $(\eta)$ and considering $\beta=2.0$ are analyzed as shown in Figure 11. As shown in Figure 11(a), the total length of the beam equals $12.0 \mathrm{~m}$, and the spans are distributed based on $\eta$ values: $L=3 \times 4.0 \mathrm{~m}$ when $\eta=1, L=(3.85+4.3+3.85) \mathrm{m} \quad$ when $\quad \eta=0.9$, $L=(3.7+4.6+3.7) \mathrm{m}$ when $\eta=0.8, L=(3.5+5.0+3.5) \mathrm{m}$ when $\eta=0.7, L=(3.25+5.5+3.25)$ mwhen $\eta=0.6$, and $L=(3.0+6.0+3.0) \mathrm{m}$ when $\eta=0.5$. As shown in Figure 11(b), the length of the main span equals $8.0 \mathrm{~m}$, and the spans are distributed based on $\eta$ values: $L=3 \times 8.0 \mathrm{~m}$ when $\eta=1, L=(7.2+8.0+7.2) \mathrm{m}$ when $\eta=0.9, L=(6.4+$ $8.0+6.4) \mathrm{m}$ when $\eta=0.8, \quad L=(5.6+8.0+5.6) \mathrm{m}$ when 


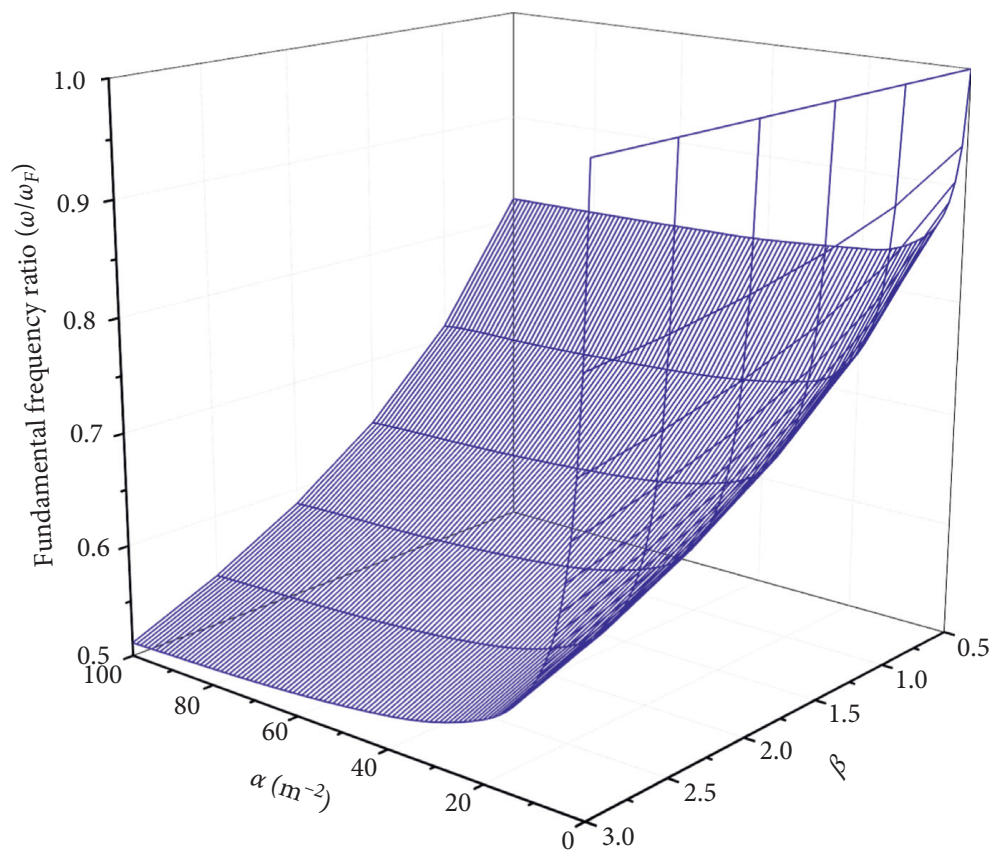

FIGURE 9: $\omega / \omega_{F}$ of SCCCB with different $\alpha$ and $\beta$.

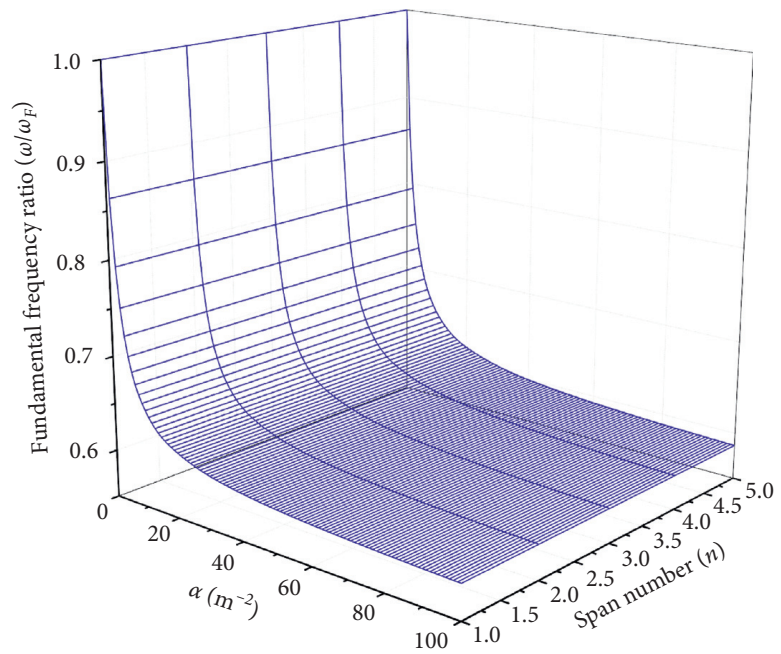

(a)

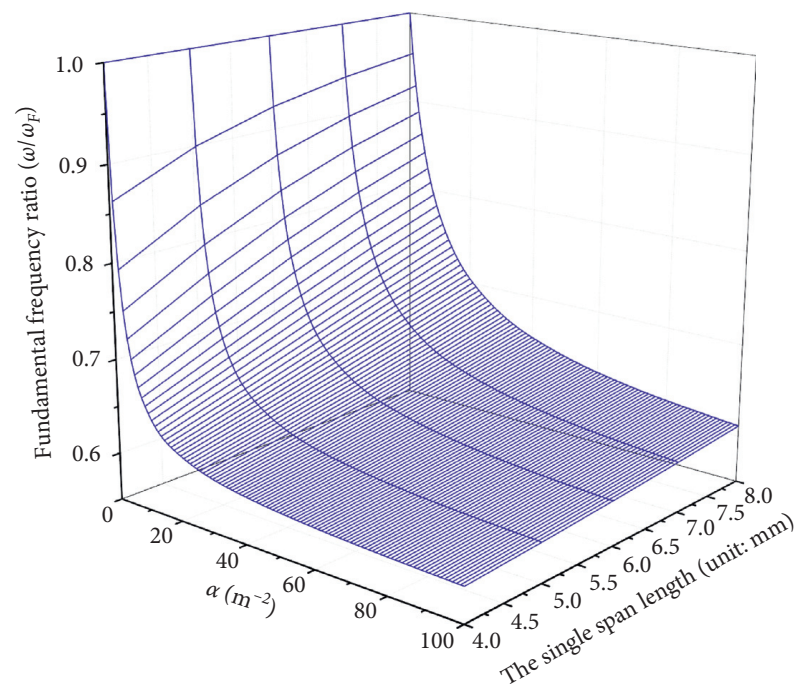

(b)

Figure 10: Values of $\omega / \omega_{F}$ of SCCCBs with different numbers of spans and single-span length. (a) The number of spans. (b) The single-span length.

$\eta=0.7, L=(4.8+8.0+4.8) \mathrm{m}$ when $\eta=0.6$, and $L=(4.0+$ $8.0+4.0) \mathrm{m}$ when $\eta=0.5$.

As shown in Figure 11(a), the values of $\omega / \omega_{F}$ are basically the same for the SCCCB with different ratios of the side span to the main span but equal total length. It indicates that the support arrangement has little effect on the influence of interfacial interaction on fundamental frequency reduction.

As shown in Figure 11(b), the values of $\omega / \omega_{F}$ exhibit significant growth with the increase of $\eta$ values for the nonzero constant value of $\alpha$. And if $\alpha \geq 0.9$, the values of $\omega / \omega_{F}$ maintain stable. It can draw a conclusion that the reasonable value of the ratio of the side span to the main $\operatorname{span}(\eta)$ is $0.9 \sim 1.0$.
3.2.4. Lumped Mass. Based on Case 2 in example 2, the influence of lumped masses on $\omega / \omega_{F}$ is analyzed as shown in Figure 12. The span length of the SCCCB is $2 \times 4.0 \mathrm{~m}$, which considers $\beta=3.0$. The values of lumped mass are $m_{1}=(0,31.8,63.6,95.4) \mathrm{kg}$, which are $(0 \%, 10 \%, 20 \%, 30 \%)$ of the weight of the beam, respectively.

Figure 12 shows that $\omega / \omega_{F}$ are basically the same for the SCCCB with different lumped masses. It reveals that the lumped masses have almost no impact on the influence of interfacial interaction on fundamental frequency reduction. The preliminary inference is due to the fact that the bending stiffness of the SCCCB is unchanged. 


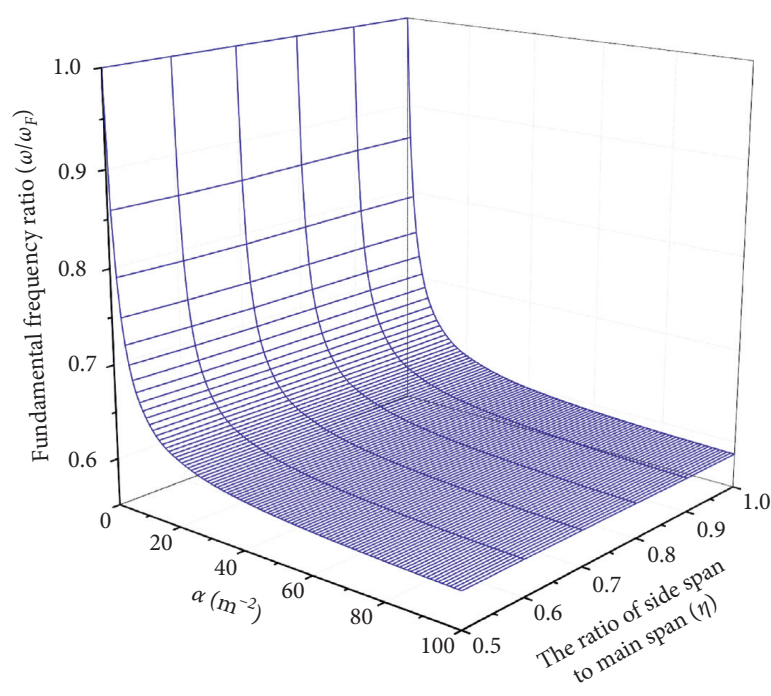

(a)

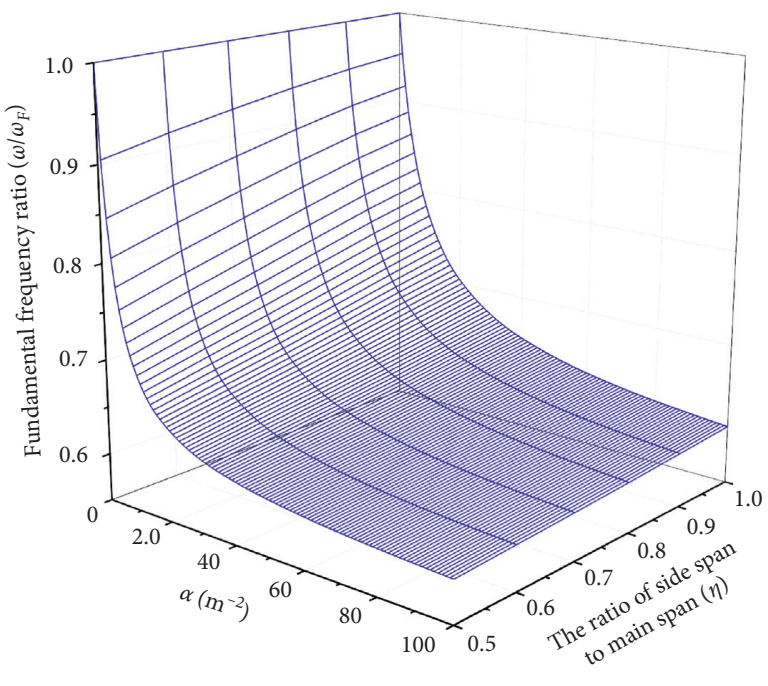

(b)

FIgURE 11: The values of $\omega / \omega_{F}$ of SCCCB with different ratios of the side span to the main span. (a) Equal total length. (b) Equal main span length.

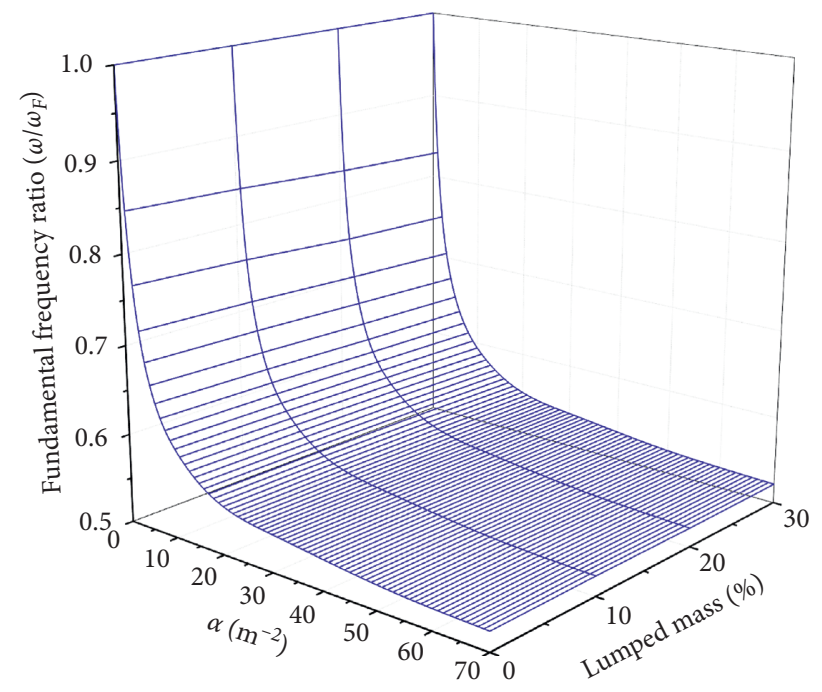

Figure 12: The values of $\omega / \omega_{F}$ of SCCCB with different lumped masses.

\section{Conclusions}

In this paper, the dynamic behaviors of SCCCBs are analyzed using a modified dynamic direct stiffness method based on Euler-Bernoulli's beam theory. The main advantages of the proposed method are that it is suitable for the SCCCBs with some lumped masses and variable bending stiffness along the $x$-direction. And the dynamic analysis results are accurate due to the elimination of approximated displacement and force fields in derivation. Further, the proposed method is verified by comparing its results with those attained using ANSYS software and laboratory tests. In addition, some influencing factors upon the natural frequencies of the SCCCBs are discussed in detail. The following conclusions are attained from this study: (i) Stronger interfacial interaction, larger steel subbeam, and thinner concrete slab lead to higher values of the natural frequency of SCCCBs. Smaller beam natural frequency leads to a greater effect of the interfacial interaction on the natural frequency for SCCCBs. It is the same as the single-span SCCBs.

(ii) The different numbers of spans but the equal singlespan length and different ratios of the side span to the main span but equal total length have almost no impact on the reduction of natural frequency. However, different single-span lengths and different ratios of the side span to the main span but equal main span length affect the reduction of natural frequency. 
(iii) The reduction of natural frequency is only affected by bending stiffness for the SCCCBs, and the lumped masses have almost no effect on it. It is the same as the simply supported SCCB, which can be concluded from the analytical solution of natural frequency $[3,4]$.

(iv) The reasonable values of the ratio of the side span to the main span $(\eta)$ for SCCCBs are $0.9 \sim 1.0$. This conclusion is useful in the design of SCCCBs.

\section{Appendix}

$$
\begin{aligned}
& B_{1}=\frac{\alpha^{2}}{\beta} \lambda_{1}^{5}+\alpha \lambda_{1}^{3}-\left[\frac{\gamma \alpha^{2}(1+\beta)}{\beta} \omega^{2}+1\right] \lambda_{1}, \\
& B_{2}=\frac{\alpha^{2}}{\beta} \lambda_{2}^{5}-\alpha \lambda_{2}^{3}-\left[\frac{\gamma \alpha^{2}(1+\beta)}{\beta} \omega^{2}+1\right] \lambda_{2}, \\
& B_{3}=\frac{\alpha^{2}}{\beta} \lambda_{3}^{5}-\alpha \lambda_{3}^{3}-\left[\frac{\gamma \alpha^{2}(1+\beta)}{\beta} \omega^{2}+1\right] \lambda_{3}, \\
& C_{1}=\frac{\alpha}{\beta} \lambda_{1}^{4}+\lambda_{1}^{2}-\frac{\gamma \alpha(1+\beta)}{\beta} \omega^{2}, \\
& C_{2}=\frac{\alpha}{\beta} \lambda_{2}^{4}-\lambda_{2}^{2}-\frac{\gamma \alpha(1+\beta)}{\beta} \omega^{2}, \\
& C_{3}=\frac{\alpha}{\beta} \lambda_{3}^{4}-\lambda_{3}^{2}-\frac{\gamma \alpha(1+\beta)}{\beta} \omega^{2}, \\
& D_{1}=(E I)_{1} C_{1} \lambda_{1}+(E I)_{2} \lambda_{1}^{3}, \\
& D_{2}=(E I)_{1} C_{2} \lambda_{2}-(E I)_{2} \lambda_{2}^{3}, \\
& D_{3}=(E I)_{1} C_{3} \lambda_{3}-(E I)_{2} \lambda_{3}^{3} .
\end{aligned}
$$

\section{Data Availability}

All the raw data used to support the findings of this study (resulting from numerical simulations) are included within the article. However, the finite element models are available from the corresponding author upon request.

\section{Conflicts of Interest}

The authors declare that they have no conflicts of interest.

\section{Acknowledgments}

The research described in this paper was financially supported by the Fundamental Research Funds for the Central Universities (2020JBM121). In addition, the authors would like to express their gratitude to EditSprings (https://www.editsprings.com/) for the expert linguistic services provided.

\section{References}

[1] U. A. Girhammar and D. Pan, "Dynamic analysis of composite members with interlayer slip," International Journal of Solids and Structures, vol. 30, no. 6, pp. 797-823, 1993.

[2] U. A. Girhammar and D. H. Pan, "Exact static analysis of partially composite beams and beam-columns," International Journal of Mechanical Sciences, vol. 49, no. 2, pp. 239-255, 2007.

[3] U. A. Girhammar, D. H. Pan, and A. Gustafsson, "Exact dynamic analysis of composite beams with partial interaction," International Journal of Mechanical Sciences, vol. 51, no. 8, pp. 565-582, 2009.

[4] Y.-F. Wu, R. Xu, and W. Chen, "Free vibrations of the partialinteraction composite members with axial force," Journal of Sound and Vibration, vol. 299, no. 4-5, pp. 1074-1093, 2007.

[5] S. Grundberg, U. A. Girhammar, and O. A. B. Hassan, "Vibration of axially loaded and partially interacting composite beams," International Journal of Structural Stability and Dynamics, vol. 14, no. 1, Article ID 1350047, 2014.

[6] C. W. Huang and Y. H. Su, "Dynamic characteristics of partial composite beams," International Journal of Structural Stability and Dynamics, vol. 8, no. 4, pp. 665-685, 2008.

[7] Z. Hou, H. Xia, and Y. Zhang, "Dynamic analysis and shear connector damage identification of steel-concrete composite beams," Steel \& Composite Structures, vol. 13, no. 4, pp. 327-341, 2012.

[8] B. Čas, I. Planinc, and S. Schnabl, "Analytical solution of three-dimensional two-layer composite beam with interlayer slips," Engneering Structures, vol. 173, no. 2018, pp. 269-282, 2018.

[9] Q. K. Sun, N. Zhang, X. Liu et al., "Free vibration characteristics of steel-concrete composite beams considering longitudinal stiffness distribution based on energy method," Journal of Vibration and Shock, vol. 40, no. 10, pp. 67-72, 2021, in Chinese.

[10] S. Berczyński and T. Wróblewski, "Vibration of steel-concrete composite beams using the Timoshenko beam model," Journal of Vibration and Control, vol. 11, no. 6, pp. 829-848, 2005.

[11] R. Q. Xu and Y. F. Wu, "Static, dynamic, and buckling analysis of partial interaction composite members using Timoshenko's beam theory," International Journal of Mechanical Sciences, vol. 49, no. 2007, pp. 1139-1155, 2007.

[12] R. Q. Xu and G. N. Wang, "Variational principle of partialinteraction composite beams using Timoshenko's beam theory," International Journal of Mechanical Sciences, vol. 60, no. 2012, pp. 72-83, 2012.

[13] M. Dilena and A. Morassi, "Vibrations of steel-concrete composite beams with partially degraded connection and applications to damage detection," Journal of Sound Vibration, vol. 320, no. 2009, pp. 101-124, 2009.

[14] Q. H. Nguyen, M. Hjiaj, and P. L. Grognec, "Analytical approach for free vibration analysis of two-layer Timoshenko beams with interlayer slip," Journal of Sound Vibration, vol. 331, no. 2012, pp. 2949-2961, 2012.

[15] Ö. Civalek, "Application of differential quadrature (DQ) and harmonic differential quadrature (HDQ) for buckling analysis of thin isotropic plates and elastic columns," Engineering Structures, vol. 26, no. 2, pp. 171-186, 2004. 
[16] O. Civalek and A. Yavas, "Large deflection static analysis of rectangular plates on two parameter elastic foundations," International Journal of Science and Technology, vol. 1, no. 1, pp. 43-50, 2006.

[17] Ö. Civalek and O. Kiracioglu, "Free vibration analysis of Timoshenko beams by DSC method," International Journal for Numerical Methods in Biomedical Engineering, vol. 26, no. 12, pp. 1890-1898, 2010.

[18] P. A. A. Laura and R. H. Gutierrez, "Analysis of vibrating Timoshenko beams using the method of differential quadrature," Shock and Vibration, vol. 15 pages, Article ID 124195, 1993.

[19] A. Chakrabarti, A. H. Sheikh, M. Griffith, and D. J. Oehlers, "Dynamic response of composite beams with partial shear interaction using a higher-order beam theory," Journal of Structural Engineering, vol. 139, no. 1, pp. 47-56, 2013.

[20] A. Chakrabarti, A. H. Sheikh, M. Griffith, and D. J. Oehlers, "Analysis of composite beams with longitudinal and transverse partial interactions using higher order beam theory," International Journal of Mechanical Sciences, vol. 59, no. 1, pp. 115-125, 2012.

[21] Q. K. Sun, N. Zhang, X. Liu et al., “An equivalent single-layer theory for free vibration analysis of steel-concrete composite beams," Steel and Composite Structures, vol. 38, no. 3, pp. 281-291, 2021.

[22] G. He and X. Yang, "Dynamic analysis of two-layer composite beams with partial interaction using a higher order beam theory," International Journal of Mechanical Sciences, vol. 90, no. 2015, pp. 102-112, 2015.

[23] G. He, D. Wang, and X. Yang, "Analytical solutions for free vibration and buckling of composite beams using a higher order beam theory," Acta Mechanica Solida Sinica, vol. 29, no. 3, pp. 300-315, 2016.

[24] C. Fu and X. Yang, "Dynamic analysis of partial-interaction Kant composite beams by weak-form quadrature element method," Archive of Applied Mechanics, vol. 88, no. 1, pp. 2179-2198, 2018.

[25] G. Fang, J. Wang, S. Li, and S. Zhang, "Dynamic characteristics analysis of partial-interaction composite continuous beams," Steel and Composite Structures, vol. 21, no. 1, pp. 195-216, 2016.

[26] J. F. Wang, J. T. Zhang, R. Q. Xu, and Z. X. Yang, "A numerically stable dynamic coefficient method and its application in free vibration of partial-interaction continuous composite beams," Journal of Sound and Vibration, vol. 457, no. 2019, pp. 314-332, 2019.

[27] J. Li, Q. Huo, X. Li, X. Kong, and W. Wu, "Dynamic stiffness analysis of steel-concrete composite beams," Steel and Composite Structures, vol. 16, no. 6, pp. 577-593, 2014.

[28] G. J. Bao and R. Q. Xu, "Dynamic stiffness matrix of partialinteraction composite beams," Advances in Mechanical Engineering, vol. 7, 2015.

[29] Q. Sun, N. Zhang, X. Liu, and X. Tao, "Free vibrations of steelconcrete composite beams by the dynamic direct stiffness method," International Journal of Structural Stability and Dynamics, vol. 21, no. 4, Article ID 2150049, 2021.

[30] N. Gattesco, "Analytical modeling of nonlinear behavior of composite beams with deformable connection," Journal of Constructional Steel Research, vol. 52, no. 2, pp. 102-112, 1999.

[31] J. G. Nie, J. M. Shen, and Y. S. Yuan, "A general formula for predicting the deflection of simply supported composite steel concrete beams with the consideration of slip effect," Engineering Mechanics, vol. 11, no. 1, pp. 21-27, 1994, in Chinese. 